\title{
Yapewa (CANOA)
}

\author{
Yrywaxã (Koria Valdvane Tapirapé) \\ Professor alfabetizador
}

\section{RESUMO}

Ã te’omara kwakãj aãpa Tapi'itãjpe 'Yapewa re, axe'egenop kwãkaj Wario, Imakopy ne. Aparanop kwee mywi ta' e rakaẽ xireka 'Yapewa, ma’ereta’e rakaẽ mi ximagy, amagyjxe ta’e rakaẽ mi, nimamaxyãwi ta'e rakaẽ mi pityga rowa we.

Epewepewera re kwãkaj aparanop.A'e kwãkaj akome'o xewe nyt: Yapewa roo xireka ypewoo wi, petora roõ rakaẽ werot, 'ywewoja roõ ywyraxiniga ne xiãpa Yapewa ramõ, ximagy roõ rakaẽ mi xigy pe, 'yaapãwa ramõ, xawaxi awyãwa ramõ. Ikwaãwa xowe roõ 'ywira, yypa ne.

Ikome’opawire xowe kwãkaj axema'eakãt marygato 'Yapewa apaãwa. Tapi'itãjpe kwãkaj axema'e 'Yapewa apaãwa re. A’ere xowe kwãkaj ama’e pitywera ee, wexewe apaãwa ropi Myryxitãjpe, wexewe kome’oãwa ropi kwãkaj akome’o pitywera we 'Yapewa paragetã.

Emanyt kwãkaj aãpa te’omara 'Yapewa re, ipoenowakãta pitywera gy we.

PALAVRAS-CHAVE: Uso de Yapewa. Origem de 'Yapewa. Construção. Materiais necessários.

\section{RESUMO}

'Ã te’omara kwakãj aãpa Tapi'itãjpe 'Yapewa re, axe’egenop kwãkaj Wario Imakopy ne. Aparanop kwee mywi ta'e rakaẽ xireka 'Yapewa, ma'ereta'e rakaẽ mi ximagy, amagyjxe ta'e rakaẽ mi, nimamaxy ãwi ta'e rakaẽ mi pityga rowa we.

Epewepewera rekwãkaj aparanop. A’e kwãkaj akome’o xewe nyt: Yapewa roo xireka ypewoo wi, petora roõ rakaẽ werot, 'ywewoja roõ ywyraxiniga ne xiãpa Yapewa ramõ, ximagy roõ raka'ẽ mi xigy 
pe, 'yaapãwa ramõ, xawaxi awyãwa ramõ. Ikwaãwa xowe roõ 'ywira, yypa ne.

Ikome’opawire xowe kwãkaj axema'eakãt mary ato 'Yapewa apaãwa. Tapi'itãpe kwãkaj axema'e Yapewa apaãwa re A’ere xowe kwãkaj ama'e pitywera ee, wexewe apaãwa ropi topistãjpe,wexewe kome’oãwa ropi kwãkaj akome’o pitywera we 'Yapewa paragetã.

Emanyt kwãkaj aãpa te'omara 'Yapewa re, ipoenowakãta pitywera gy we.

PALAVRAS-CHAVE: Uso de Yapewa. Origem de 'Yapewa. Construção. Materiais necessários.

\section{INTRODUÇÃO}

A atividade desenvolvida sobre Yapewa foi o momento que trouxe como principal foco o acompanhamento da construção do Yapewa, desenvolvido pelos mestres Wario e Imakopy, reflexões sobre o não uso de Yapewa. Digamos que não podemos levar o conhecimento somente na teoria e sim na prática, para a orientação sobre alfabetização de modo geral, ou seja, os meninos, os rapazes e os homens adultos. É preciso discutir de maneira aprofundada a questão/temática Yapewa, que era relacionada ao cotidiano da vida do povo Apyãwa, e que hoje é distanciada devido à sociedade envolvente, que influencia no seu aspecto natural, social, econômico, cultural, político, e que precisa ser discutida também no processo educacional formal do povo Apyãwa. Oportunizou-se também durante o trabalho desenvolvido somar os conhecimentos dos (as) alunos (as) e o meu conhecimento.

\section{OBJETIVOS}

A atividade sobre Yapewa teve os seguintes objetivos:

- Compreender o processo histórico da Yapewa.

- Compreender a construção de Yapewa com entrevistado.

- Reconstruir Yapewa juntamente com os alunos alfabetizandos, no processo de construção e na utilização. 


\section{ATIVIDADES}

Para ser realizada a atividade sobre a construção de Yapewa, fui entrevistar os senhores Wario e Imakopy, na aldeia Tapi itãwa. Ambos são moradores desta aldeia, onde busquei as informações concretas a partir de várias indagações. Como posso destacar: a origem de Yapewa, os materiais necessários, onde eram utilizados e em que período eram utilizados mais. Referi-me também a perguntar sobre o uso de Yapewa, se era permitida para qualquer pessoa.

De acordo com as minhas interrogações foram frisadas as respostas. Neste processo consegui captar as informações exatas, tirando as dúvidas referentes ao tema Yapewa. Segundo os entrevistados, Yapewa foi trazido de Ypewoo (pato). Quem trouxe foi o Petora. A partir disso sistematizei as informações, isto é, as respostas das minhas perguntas, para que sejam repassadas para os/as alunos/ as. Como, por exemplo, os materiais necessários são: ywyrãxiniga, ywewoja (pau seco que boia na superfície da água), ywira (embira), уура (cipó). O lugar onde era utilizada: rio (para atravessar o rio), lago (onde ocorria a pescaria com timbó, a pescaria de tartaruga e assim sucessivamente.

Antes de repassar as informações e levar os alunos na prática, preparei-me detalhadamente no processo de construção de Yapewa, com o senhor Imakopy, na aldeia Tapi itãwa. Alfabetizei-me do tipo de pau que serve para a construção de Yapewa, como é amarrado o pau entre as outras com ywira (embira) ou yypa (espécie resistente do cipó), para depois construir um Yapewa juntamente com os alunos.

À medida que repassei as informações, especificamente do seu uso, que era utilizado para travessia do rio ou do lago, a pescaria cerimonial com timbó e a pescaria de tartaruga com a flecha, simultaneamente, ressaltei o tema Yapewa, que a gente iria construir um. Percebi que os alunos tiveram a curiosidade enorme para compreender o que foi aquilo. Até porque o nome é desconhecido pelos alunos.

Portanto, fomos na prática a confeccionar Yapewa, quando os alunos conheceram a sua característica e aprenderam as suas importâncias, o seu valor, como também o processo de construção. Assim este trabalho foi desenvolvido. 